\title{
Novel Notched UWB Filter Using Stepped Impedance Stub Loaded Microstrip Resonator and Spurlines
}

\author{
Ramkumar Uikey, ${ }^{1}$ Ramanand Sagar Sangam, ${ }^{1}$ \\ Kakumanu Prasadu, ${ }^{2}$ and Rakhesh Singh Kshetrimayum ${ }^{1}$ \\ ${ }^{1}$ Department of Electronics \& Electrical Engineering, IIT Guwahati, Assam 781039, India \\ ${ }^{2}$ Ford Motor Pvt. Ltd., Dr. MGR Road, Perungundi, Chennai 600096, India \\ Correspondence should be addressed to Rakhesh Singh Kshetrimayum; krs@iitg.ernet.in
}

Received 10 June 2015; Revised 15 August 2015; Accepted 19 August 2015

Academic Editor: Giancarlo Bartolucci

Copyright (C) 2015 Ramkumar Uikey et al. This is an open access article distributed under the Creative Commons Attribution License, which permits unrestricted use, distribution, and reproduction in any medium, provided the original work is properly cited.

\begin{abstract}
This paper presents a novel ultrawideband (UWB) bandpass filter using stepped impedance stub loaded microstrip resonator (SISLMR). The proposed resonator is so formed to allow its four resonant frequencies in the UWB passband, which extends from $3.1 \mathrm{GHz}$ to $10.6 \mathrm{GHz}$. Moreover, two spurline sections are employed to create a sharp notched-band filter for suppressing the signals of $5 \mathrm{GHz}$ WLAN devices. Experimental results of the fabricated filters are in good agreement with the HFSS simulations and validate the design.
\end{abstract}

\section{Introduction}

Since the release of UWB spectrum by the Federal Communications Commission for unlicensed commercial applications in early 2002 [1], compact size UWB bandpass filters with good in-band transmission, sharp selectivity, and flat group delays are highly demanded to realize UWB radio systems. A number of methods have been reported in the literature $[2-8]$ to design the UWB bandpass filters. An early method reported in [2] is based on cascaded low-pass-high-pass filter sections. A hybrid microstrip/CPW structure with back-toback transition configuration is used in [3] to achieve the UWB bandpass response. In [4], a stepped impedance fourmode resonator is developed on the method of network analysis and optimization in Z-domain. Today, a major class of available UWB filters are based on the multiple-mode resonators (MMR) and are quite popular due to their easy design methods and simple structures. The concept of MMR based UWB filter was initially presented in [5]. In this work, a triple-mode MMR is integrated with dual-pole overenhanced parallel coupled lines to realize the UWB filter. This work is extended in [6] to get a more feasible filter with relaxed fabrication tolerance. In $[7,8]$, open ended stub loaded resonator based UWB filters are designed to widen the upper stopband.

In recent years, researchers are more attracted towards filters with notch bands embedded in the UWB passband. These notch bands are required to suppress the strong narrowband emissions in the WLAN and WiMAX bands which coincide with the $3.1 \mathrm{GHz}$ to $10.6 \mathrm{GHz}$ UWB spectrum. Many efforts have been put forward by researchers in [9-12], to design notched-band UWB filters. A Meander line slot is developed in [9] to reject the undesired IEEE 802.11a signals. Symmetrical pairs of defected ground structure with embedded open stubs are employed to create the WLAN notch [10]. In [11], five short circuited stubs are incorporated in the design to exhibit highly selective filtering characteristics. In our early work [12], we designed a notched-band bandpass filter using complementary single split ring resonators in the ground plane. All above mentioned filters possess good notch band filtering but they are either based on defected ground structures or suffer from fabrication difficulties due to via holes. Hence, emphasis is given to planar structures, which are free from via holes and defected ground structures.

In this paper, we are proposing a novel quad-mode stepped impedance stub loaded microstrip resonator 


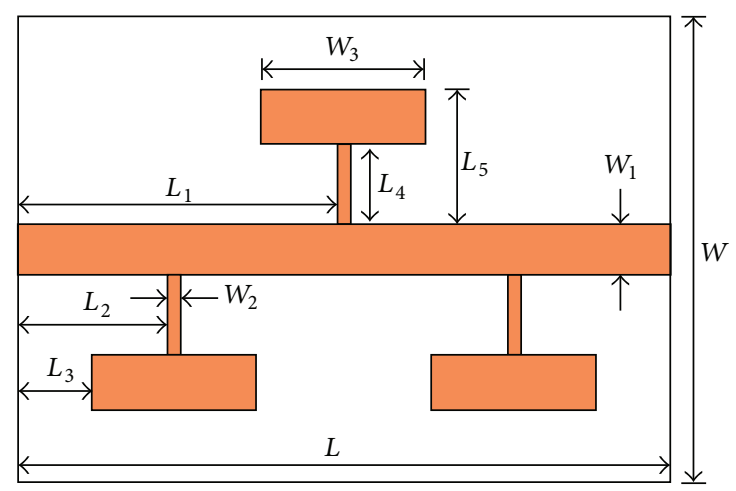

Figure 1: Basic structure of the proposed stepped impedance stub loaded UWB bandpass filter.

(SISLMR) to design the UWB bandpass filters. It is constructed by loading a uniform $50 \Omega$ transmission line with three symmetrical stepped impedance stubs, that is, one at the center and two at the symmetrical side locations. Then two symmetrical spurline sections are developed around the central stepped impedance stub to create a sharp notch band for suppressing the WLAN radio systems operating in the $5 \mathrm{GHz}$ frequency bands. Finite element based Anosoft HFSS software is used for deriving the filter's electrical performance; later, two filter prototypes, one with notch band and one without notch band, are fabricated and measured for experimental verification of the predicted results.

\section{Initial UWB Filter Design}

Figure 1 depicts the schematic of the proposed resonator. It consists of a conventional transmission line resonator $(50 \Omega)$ of width $W_{1}$ and length $2 L_{1}+W_{2}$ in the horizontal plane and three vertically loaded stepped impedance stubs, that is, one stepped impedance stub of width $W_{2}, W_{3}$, length $L_{4}, L_{5}$ at the center and the other two stubs of the same dimensions at the symmetrical sides, located at a distance of about $\lambda_{g} / 4$ from the central stub. In the initial design, we load a $50 \Omega$ transmission line $\left(\approx 1.5 \lambda_{g}\right)$ with single stepped impedance at the center. When impedance ratio for this stepped impedance stub is set close to 0.2 , we observe some UWB filtering characteristics with two transmission zeros near 2 and $11 \mathrm{GHz}$, respectively, and a pole near $6.5 \mathrm{GHz}$. Later, this initial resonator structure is modified by introducing two more stepped impedance stubs to have a higher degree of freedom in the design. A parametric analysis is performed using FEM based HFSS software and resonator parameters are optimized to achieve the UWB bandpass response. Optimized electrical parameters for the proposed SISLMR are given in Table 1 and HFSS simulated results are shown in Figure 2. Simulation results depict that the proposed resonator has four resonant frequencies in the desired passband, located at 3.43, 5.20, 7.40, and $9.38 \mathrm{GHz}$, respectively. Transmission zeros in the lower and upper stopband are located at 2.17 and $10.97 \mathrm{GHz}$, respectively. Designed filter demonstrates good UWB filtering with $\left|S_{21}\right| \geq$
TABLE 1: Design parameter values for Figure 1.

\begin{tabular}{llc}
\hline$L=38 \mathrm{~mm}$ & $W=32 \mathrm{~mm}$ & FR4-epoxy substrate \\
\hline$L_{1}=18.75 \mathrm{~mm}$ & $W_{1}=3.1 \mathrm{~mm}$ & $\epsilon_{r}=4.4$ \\
\hline$L_{2}=7.75 \mathrm{~mm}$ & $W_{2}=0.5 \mathrm{~mm}$ & $h=1.6 \mathrm{~mm}$ \\
\hline$L_{3}=3.5 \mathrm{~mm}$ & $W_{3}=9.5 \mathrm{~mm}$ & $t=0.035 \mathrm{~mm}$ \\
\hline$L_{4}=6.5 \mathrm{~mm}$ & & $\tan \delta=0.002$ \\
\hline$L_{5}=9.5 \mathrm{~mm}$ & & \\
\hline
\end{tabular}

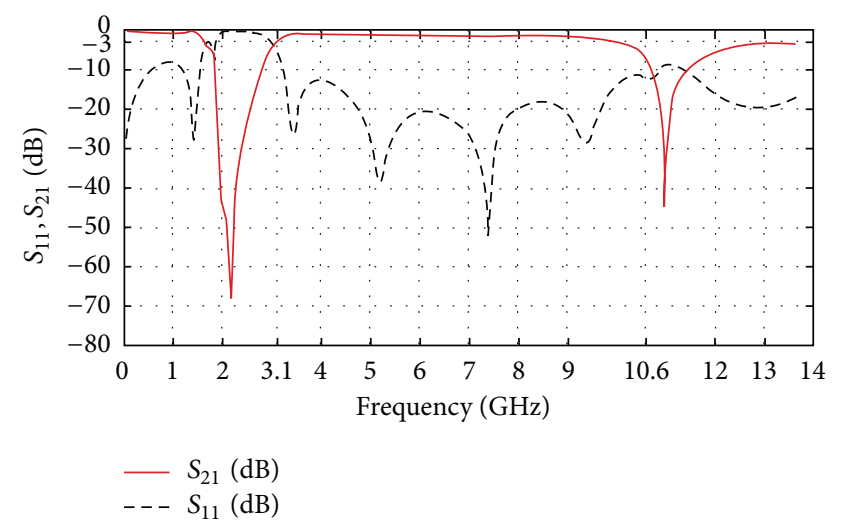

FIGURE 2: Simulated frequency response of the designed UWB bandpass filter.

$-3 \mathrm{~dB}$ and $\left|S_{11}\right| \leq-10 \mathrm{~dB}$ and flat group delay in the desired UWB spectrum.

2.1. Approximate Theoretical Analysis. This section describes an approximate theoretical analysis of the proposed resonator. It considers the case of lossless transmission lines and ignores the effects of step discontinuities, frequency dispersion, and edge capacitances at the open stubs.

Figure 3 shows the transmission line model of the proposed resonator. The overall ABCD matrix, $[R]$, in Figure 3 can be obtained by multiplying the ABCD matrices of the terminal lines, connecting lines between stepped impedance stubs and stepped impedance stubs in sequence; that is,

$$
[R]=[A][B][C][B][C][B][A],
$$

where

$$
\begin{aligned}
& {[A]=\left[\begin{array}{cc}
\cos \left(\theta_{1}^{\prime}\right) & \frac{j \sin \left(\theta_{1}^{\prime}\right)}{Y_{1}} \\
j Y_{1} \sin \left(\theta_{1}^{\prime}\right) & \cos \left(\theta_{1}^{\prime}\right)
\end{array}\right],} \\
& {[B]=\left[\begin{array}{cc}
1 & 0 \\
j Y_{2} \frac{Y_{2} \tan \left(\theta_{3}\right)+Y_{1} \tan \left(\theta_{2}\right)}{Y_{1}-Y_{2} \tan \left(\theta_{2}\right) \tan \left(\theta_{3}\right)} & 1
\end{array}\right],} \\
& {[C]=\left[\begin{array}{cc}
\cos \left(\theta_{1}\right) & \frac{j \sin \left(\theta_{1}\right)}{Y_{1}} \\
j Y_{1} \sin \left(\theta_{1}\right) & \cos \left(\theta_{1}\right)
\end{array}\right] .}
\end{aligned}
$$




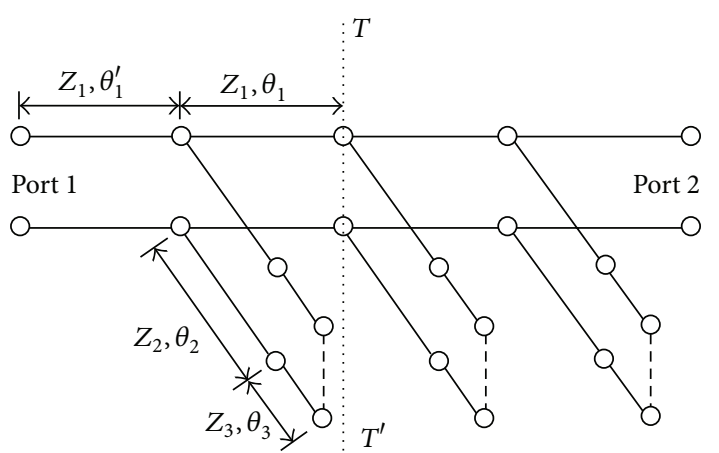

FIgURE 3: Transmission line model of the proposed UWB bandpass filter.

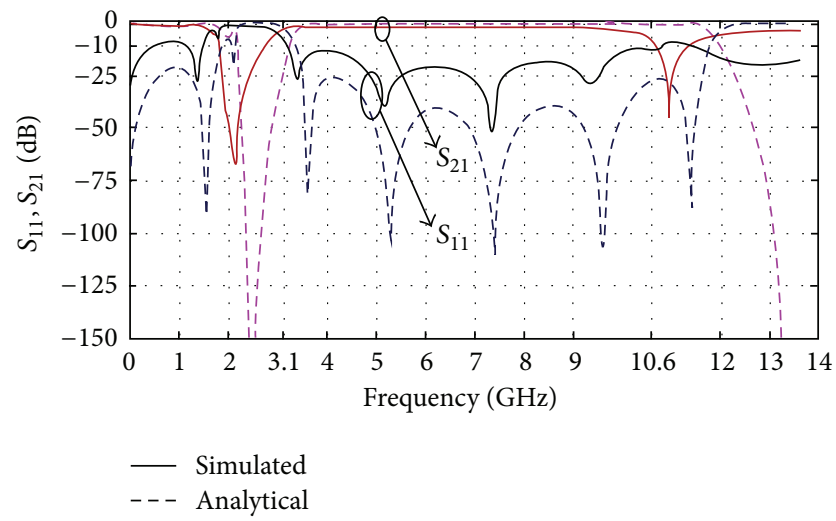

FIGURE 4: Comparison of simulated and analytical results.

Using (1) and matched load condition at port 2, $\left|S_{21}\right|(\mathrm{dB})$ and $\left|S_{11}\right|(\mathrm{dB})$ for the resonator in Figure 1 are deduced as

$$
\begin{aligned}
& \left|S_{21}\right|=20 \\
& \quad \cdot \log \left(\frac{2 \sqrt{Z_{01} / Z_{02}}}{R_{11}+R_{12} / Z_{02}+R_{21} Z_{01}+R_{22}\left(Z_{01} / Z_{02}\right)}\right) \mathrm{dB}, \\
& \left|S_{11}\right|=20 \\
& \quad \cdot \log \left(\frac{R_{11}+R_{12} / Z_{02}-R_{21} Z_{01}-R_{22}\left(Z_{01} / Z_{02}\right)}{R_{11}+R_{12} / Z_{02}+R_{21} Z_{01}+R_{22}\left(Z_{01} / Z_{02}\right)}\right) \mathrm{dB} .
\end{aligned}
$$

$Z_{01}$ and $Z_{02}$ in the above equations are source and load impedances, respectively. In Figure 4, analytical results of (3) are plotted in MATLAB and compared with the HFSS simulated results. This plot shows good match between the two results and further supports the validity of the proposed SISLMR for designing the UWB bandpass filters.

\section{Realization of Notched-Band UWB Filter}

UWB filter designed in the previous section is modified by introducing two symmetrical spurlines to create a sharp notch function in the UWB passband. Figure 5 shows the circuit of modified UWB filter. In the modified filter, all the parameters of the initial UWB filter are kept unchanged while dimensions of the two spurlines are set as length $(a)$, gap $(b)$,

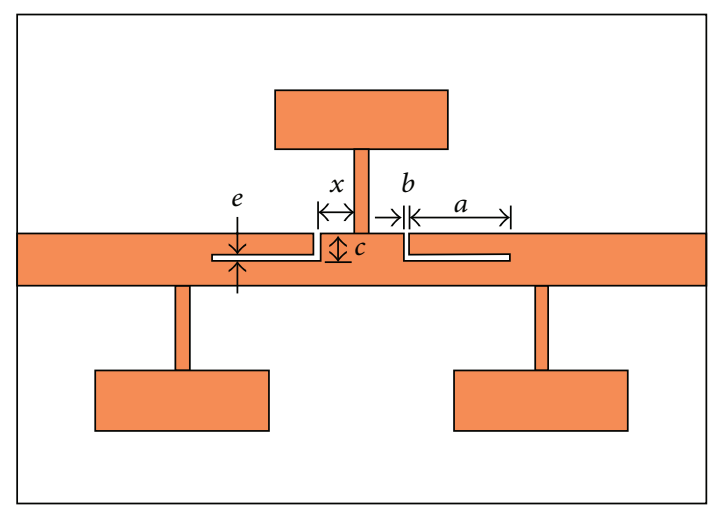

FIGURE 5: UWB filter with spurlines for realizing WLAN notch band.

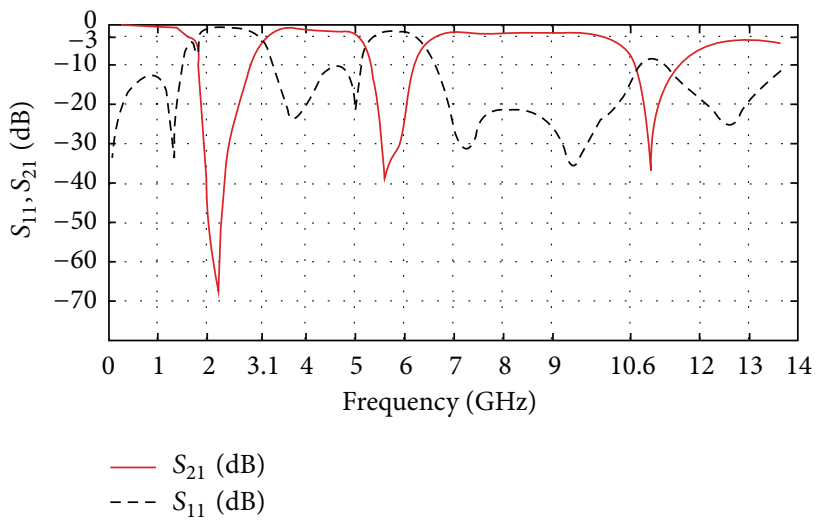

FIGURE 6: Simulated S-parameter of the notched-band UWB bandpass filter.

TABLE 2: Design parameter values for the spurlines.

\begin{tabular}{ll}
\hline$a=7 \mathrm{~mm}$ & $b=0.3 \mathrm{~mm}$ \\
\hline$c=1 \mathrm{~mm}$ & $e=0.3 \mathrm{~mm}$ \\
\hline$x=3.1 \mathrm{~mm}$ & \\
\hline
\end{tabular}

and height $(c)$, respectively. These are etched symmetrically at a distance of $x$, around the central stepped impedance stub. Length $(a)$ and gap $(b)$ of spurlines play a key role in adjusting the stopband center frequency [13], and therefore these are properly optimized using HFSS software so that the resulting notched-band filter can completely suppress the interference from WLAN devices, operating in the $5 \mathrm{GHz}$ band. Table 2 lists the optimized parameters of the proposed spurline sections.

Figure 6 shows the variation of HFSS simulated Sparameters with frequency for the notched-band UWB filter. This filter exhibits a $10 \mathrm{~dB}$ stopband from 5.15 to $6.6 \mathrm{GHz}$ with minimum $\left|S_{21}\right|$ of $-39 \mathrm{~dB}$ at $5.6 \mathrm{GHz}$ and completely eliminates the $5 \mathrm{GHz}$ WLAN bands. Furthermore, it has two $10 \mathrm{~dB}$ passbands in the desired UWB spectrum: the first passband covers a frequency range extending from 3.2 to $5.15 \mathrm{GHz}$ while the second passband covers 6.6 to $10.8 \mathrm{GHz}$ band. 


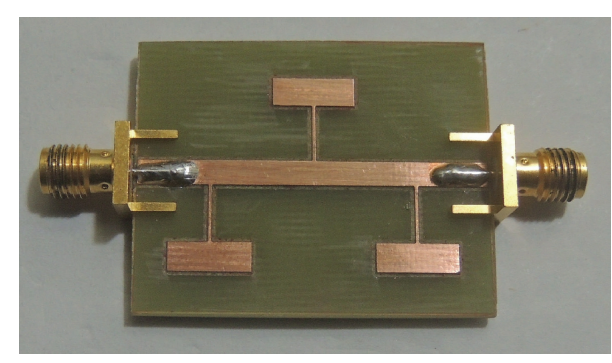

(a)

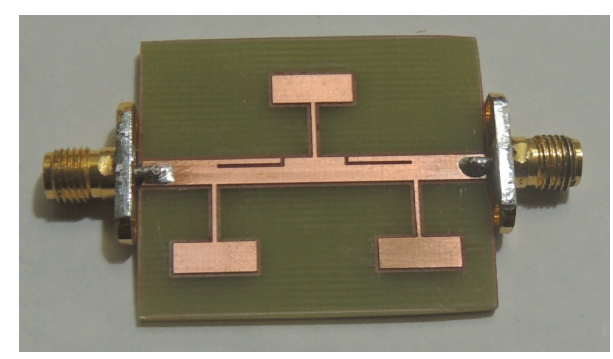

(b)

FIGURE 7: Fabricated filters. (a) Initial UWB bandpass filter and (b) notched-band UWB filter.

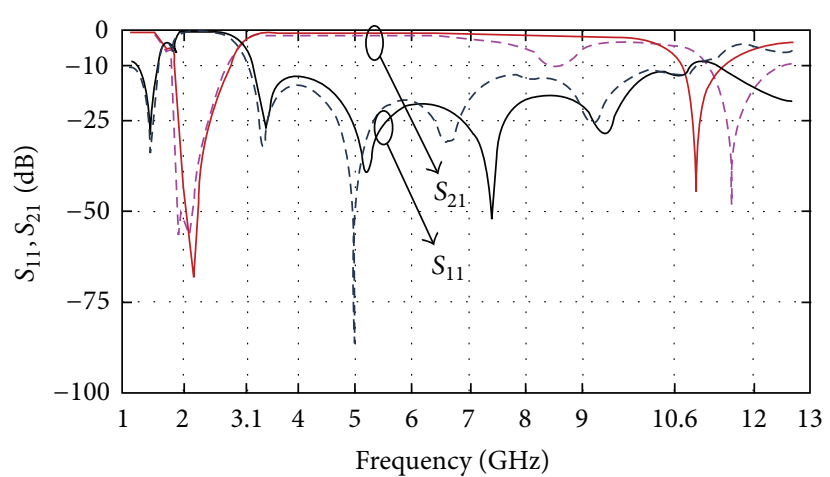

- Simulated

- - - Measured

(a)

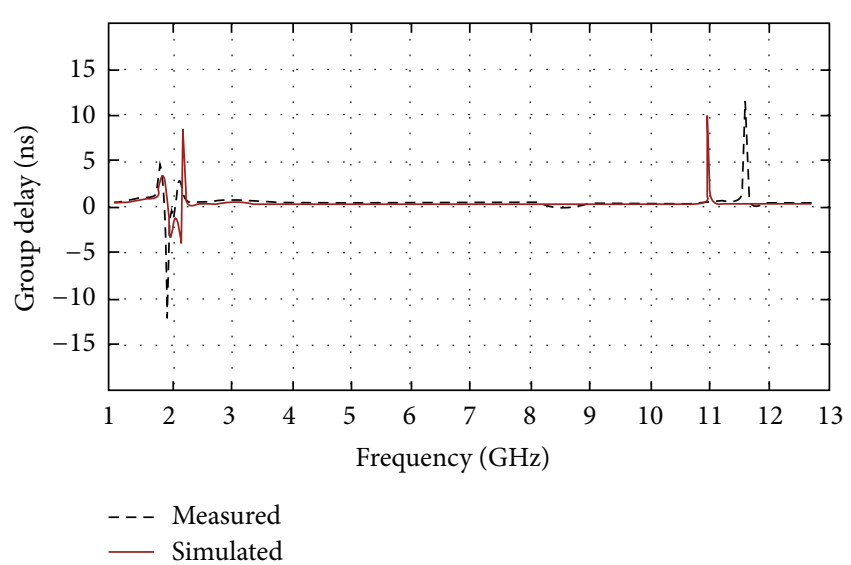

(b)

FIGURE 8: Comparison of simulated and experimental results for the initial UWB filter: (a) S-parameters and (b) group delay.

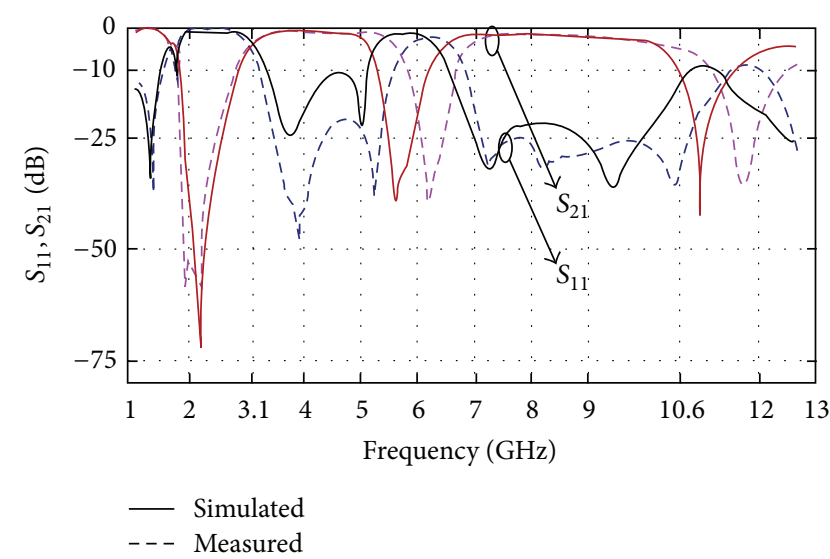

(a)

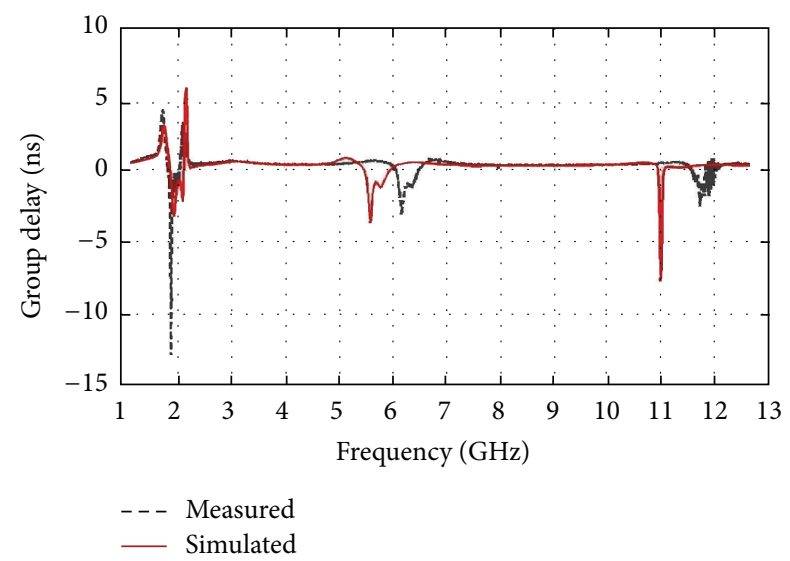

(b)

FIGURE 9: Comparison of simulated and experimental results for the notched-band UWB filter: (a) S-parameters and (b) group delay.

\section{Comparison with Experimental Results}

After deriving the optimized electrical parameters for the proposed UWB filters, the two filter prototypes are fabricated and measured using VNA for experimental verification. Figure 7 shows the photograph of fabricated filters. Simulated and measured $S$-parameters and group delay for the initially designed UWB filter and notch band UWB filter are plotted together in Figures 8 and 9, respectively, for quantitative comparison. These graphs show a good match between the two results. For the initial UWB filter, measured $10 \mathrm{~dB}$ passband extends from 3.1 to $11 \mathrm{GHz}$, while for the notchedband filter measured stopband extends from 5.5 to $6.8 \mathrm{GHz}$ and the two passbands cover $3.15-5.5 \mathrm{GHz}$ and $6.8-11.4 \mathrm{GHz}$ bands, respectively. For both filters, maximum group delay variation is better than $0.7 \mathrm{~ns}$. The two fabricated filters are 
compact in size and do not incorporate any defected ground structures or via hole connections. Some minor discrepancies are observed in the measured results which may be caused due to unexpected tolerances in fabrication and substrate parameters similar to what has been reported in [14].

\section{Conclusion}

In this paper, we proposed a novel stepped impedance stub loaded microstrip resonator (SISLMR) for designing the UWB bandpass filters. Initial UWB filter is designed by loading three double section stepped impedance stubs to the main $50 \Omega$ microstrip line, and an approximate theoretical analysis is also presented. Later on, the required WLAN notch band is designed using the spurline method. After optimization of filter parameters in HFSS software, two compact size UWB filters were fabricated and measured for experimental verification. Measured and simulated results are in good agreement with each other and validate the design.

\section{Conflict of Interests}

The authors declare that there is no conflict of interests regarding the publication of this paper.

\section{References}

[1] Federal Communications Commission, "Revision of part 15 of the commission's rules regarding ultra-wideband transmission systems," Tech. Rep. ET-Docket 98-153, FCC02-48, Federal Communications Commission (FCC), Washington, DC, USA, 2002.

[2] C.-L. Hsu, F.-C. Hsu, and J.-T. Kuo, "Microstrip bandpass filters for Ultra-Wideband (UWB) wireless communications," in Proceedings of the IEEE MTT-S International Microwave Symposium Digest, pp. 679-682, IEEE, Long Beach, Calif, USA, June 2005.

[3] H. Wang, L. Zhu, and W. Menzel, "Ultra-wideband bandpass filter with hybrid microstrip/CPW structure," IEEE Microwave and Wireless Components Letters, vol. 15, no. 12, pp. 844-846, 2005.

[4] P. Cai, Z. Ma, X. Guan, Y. Kobayashi, T. Anada, and G. Hagiwara, "A novel compact ultra-wideband bandpass filter using a microstrip stepped-impedance four-modes resonator," in Proceedings of the IEEE MTT-S International Microwave Symposium (IMS '07), pp. 751-754, IEEE, Honolulu, Hawaii, USA, June 2007.

[5] L. Zhu, S. Sun, and W. Menzel, "Ultra-Wideband (UWB) bandpass filters using multiple-mode resonator," IEEE Microwave and Wireless Components Letters, vol. 15, no. 11, pp. 796-798, 2005.

[6] L. Zhu and H. Wang, "Ultra-wideband bandpass filter on aperture-backed microstrip line," Electronics Letters, vol. 41, no. 18, pp. 1015-1016, 2005.

[7] R. Li and L. Zhu, "Compact UWB bandpass filter using stubloaded multiple-mode resonator," IEEE Microwave and Wireless Components Letters, vol. 17, no. 1, pp. 40-42, 2007.

[8] Q.-X. Chu and S.-T. Li, "Compact UWB bandpass filter with improved upper-stopband performance," Electronics Letters, vol. 44, no. 12, pp. 742-743, 2008.
[9] G.-M. Yang, R. Jin, C. Vittoria, V. G. Harris, and N. X. Sun, "Small Ultra-wideband (UWB) bandpass filter with notched band," IEEE Microwave and Wireless Components Letters, vol. 18, no. 3, pp. 176-178, 2008.

[10] W. Zong, X. Zhu, C. You, and J. Wang, "Design and implement of compact UWB bandpass filter with a frequency notch by consisting of coupled Microstrip line structure, DGS and EOS," in Proceedings of the International Conference on Advanced Technologies for Communications, pp. 179-182, Haiphong, Vietnam, October 2009.

[11] H. Shaman and J.-S. Hong, "Ultra-wideband (UWB) bandpass filter with embedded band notch structures," IEEE Microwave and Wireless Components Letters, vol. 17, no. 3, pp. 193-195, 2007.

[12] S. S. Karthikeyan and R. S. Kshetrimayum, "Notched UWB bandpass filter using complementary single split ring resonator," IEICE Electronics Express, vol. 7, no. 17, pp. 1290-1295, 2010.

[13] R. N. Bates, "Design of microstrip spur-line band-stop filters," IEE Journal on Microwaves, Optics and Acoustics, vol. 1, no. 6, pp. 209-214, 1977.

[14] P. Cai, Z. Ma, X. Guan et al., "A compact UWB bandpass filter using two-section open-circuited stubs to realize transmission zeros," in Proceedings of the Asia-Pacific Microwave Conference (APMC '05), vol. 5, Suzhou, China, December 2005. 

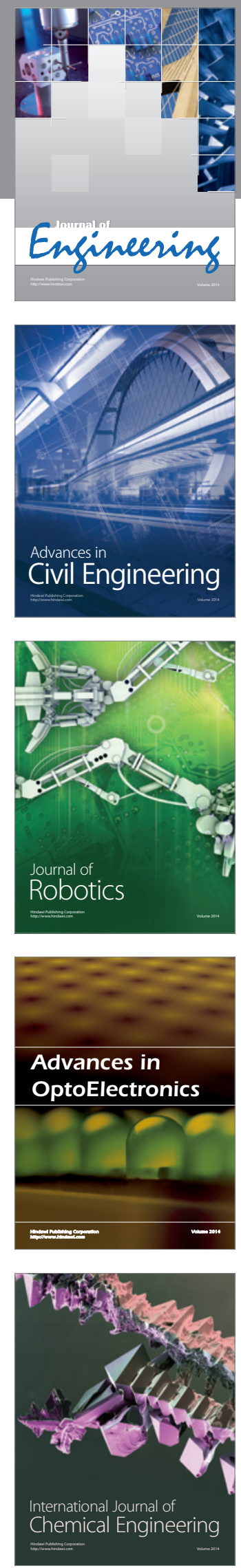

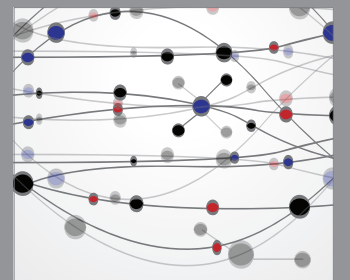

The Scientific World Journal
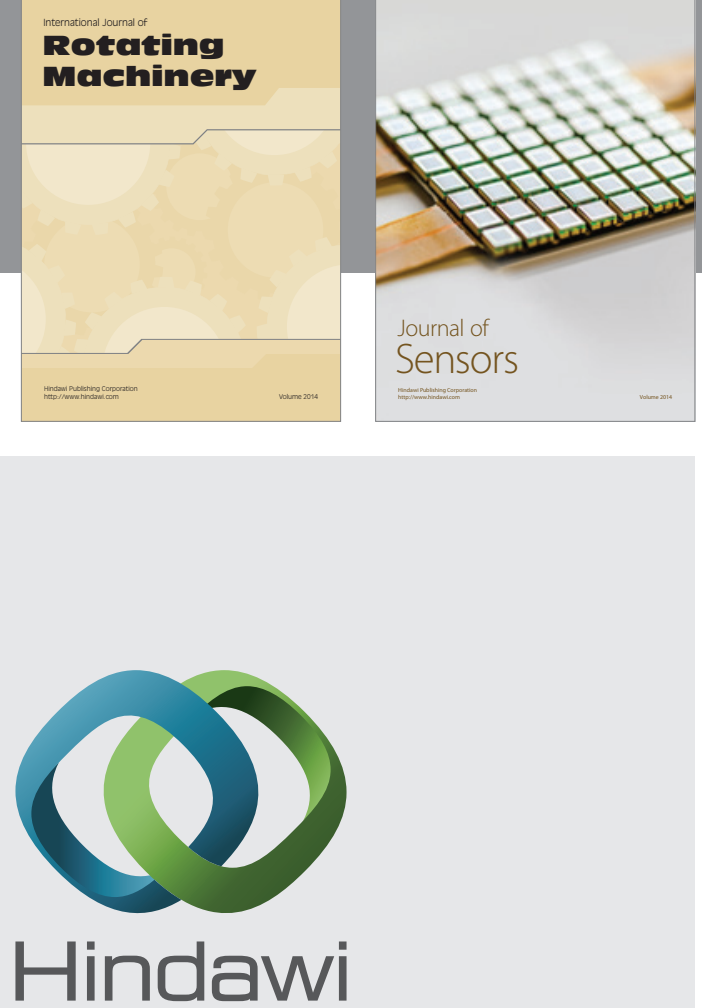

Submit your manuscripts at http://www.hindawi.com
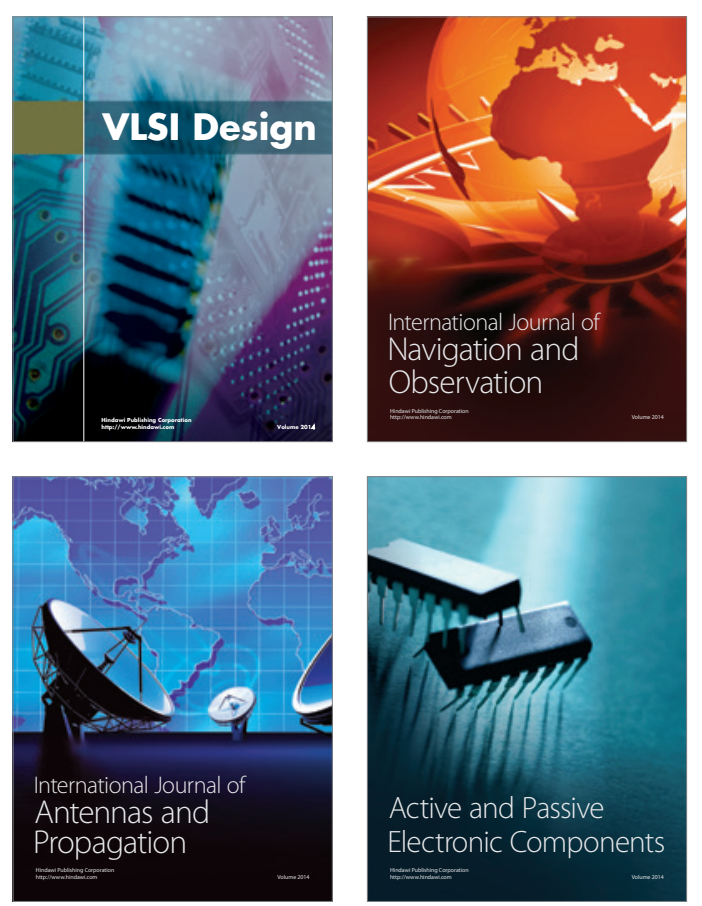
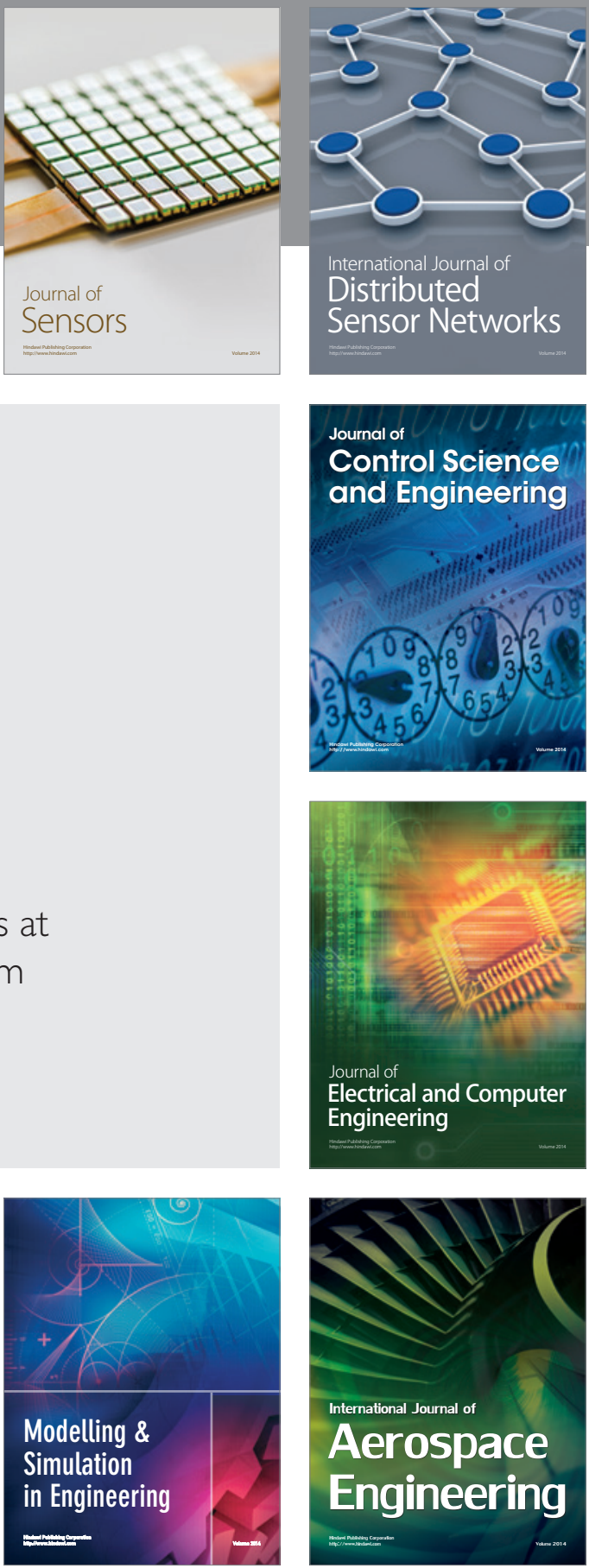

Journal of

Control Science

and Engineering
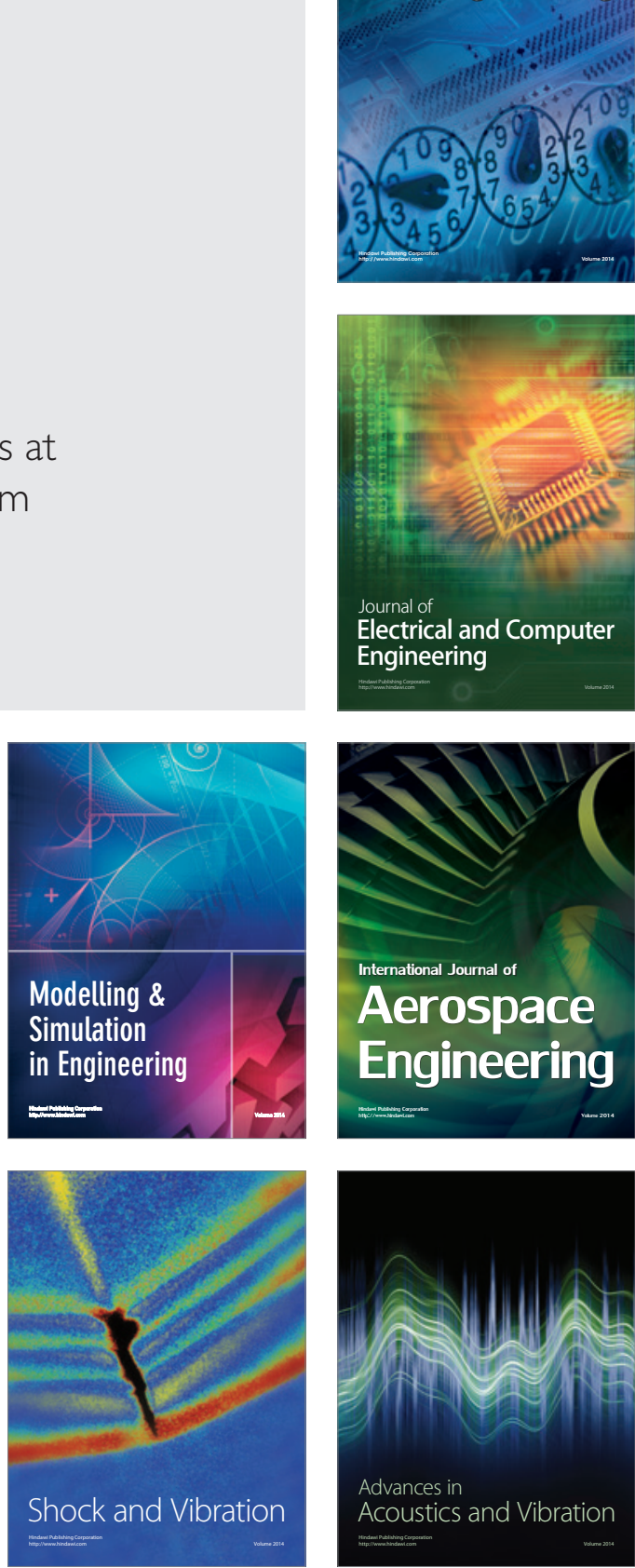